\title{
DEM Simulation and Analysis for Drop-Weight Experiments of Barite Concrete Beam
}

\author{
Zhenfu Chen ${ }^{1, a}$, Longbin $\mathrm{Li}^{1, \mathrm{~b}}$, Qiuwang Tao ${ }^{1, \mathrm{c}^{*}}$ \\ Yuanchu Gan ${ }^{1, \mathrm{~d}}$ and Xiqi Liu, ${ }^{1, \mathrm{e}}$ \\ ${ }^{1}$ School of urban construction, University of South China, Hengyang, 421001, China \\ aczf37@163.com, ${ }^{\mathrm{b}}$ lilongbin52@163.com, ${ }^{\mathrm{c} 27662321 @ q q . c o m,{ }^{d} 454408950 @ q q . c o m,}$ \\ 863225578@qq.com
}

\begin{abstract}
Keywords: barite concrete; particle flow code in two dimensions; numerical simulation; strain rate; failure mode

Abstract. A meso-scale discrete element model(DEM)of barite concrete beam was developed by the aid of DEM software PFC2D. Using this model, numerical simulations of the test conditions in meso-scale were conducted as well. The dynamic failure process of barite concrete was simulated by changing the quality and drop height of the hammer under the condition of strain rates ranging from $1.4 \mathrm{~s}^{-1}$ to $4.0 \mathrm{~s}^{-1}$, which got the curve of force histories, vertical deflection histories and strain histories. The results of simulation match well with the measurements, thus the model is validated experimentally. Compared with the failure mode at low strain rates, the failure mode at high strain rates suggests that the occurrence of more cracks is the key factor for the strain-rate effects in concrete.
\end{abstract}

\section{Introduction}

With the development of nuclear reactor technology as well as the implementation of the national long-term nuclear power development plan, the application of radiation shielding concrete will be increasingly extensive. In our daily life, Radiation shielding concrete(i.e., concrete with radiation protection ability)is called shielding or anti-radiation concrete[1]. Barite concrete, as a kind of common radiation shielding concrete, is widely used in harmful ray source project, and the main materials of which are aggregate like barite gravel and sand(the main ingredient is $\mathrm{BaSO}_{4}$ )instead of common one[2]. Barite concrete beam formed in accordance with the corresponding mixing ratio has a good protective effect on radiation for its density as well as combined water.

From the microscopic point of view, concrete beam is an inhomogeneous material composed of aggregate, mortar and interface, which forms the micro-cracks in general defects under the load. The formation and interaction of micro-cracks lead to the macro-cracks, i.e, the meso-damage failure process of concrete material[3,4]. The meso structure of concrete has an impact on the mechanical properties of concrete, such as damage localization, rate effect, etc. Thus, the development of concrete meso mechanical model contributes to the study on mechanical behavior of materials from the aspect of failure mechanism[5]. Besides, it's hard to get the granular medium constitutive model by field test, but the gradual enhancement of computer functions makes it possible be because some of the constitutive feature can be automatically formed in the model.

\section{Numerical model}

PFC in brief. The PFC programs provide a general purpose, distinct-element modeling(DEM) framework that includes both a computational engine and a graphical user interface. DEM was introduced by Cundall in 1971 for the analysis of rock-mechanics problems[6]. PFC2D(i.e., particle flow code in two dimensions) tends to simulate the mutual movement and interaction of circular granular media by means of discrete element[7,8]. The particles are rigid bodies with finite mass that move independently of one another, which can both translate and rotate. Particles interact at pair-wise contacts by means of an internal force and moment. Contact mechanics is embodied in 
particle-interaction laws that update the internal forces and moments. The time evolution of this system is computed via the distinct-element method, which provides an explicit dynamic solution to Newton's laws of motion.

Contact model of particles element. PFC2D can directly simulate both the mutual movement and interaction of circular granular media,it may also be connected by two or more adjacent particles to form a combination of arbitrary shape to simulate the block structure. The following unite to simulate the contact process is available: (1)linear spring or Hertz-mindin rule; (2)coulomb slider; (3)type of connection can be connected like point contact and parallel spring connection. parallel bond model assumes that disk centered on the contact point between particles is a series of parallel springs, which can transfer the forces and moments between particles, as shown in Fig.1. Considering the limitations in contact bond model, it will be better to simulate the drop-weight test of barite concrete by using parallel bond model.

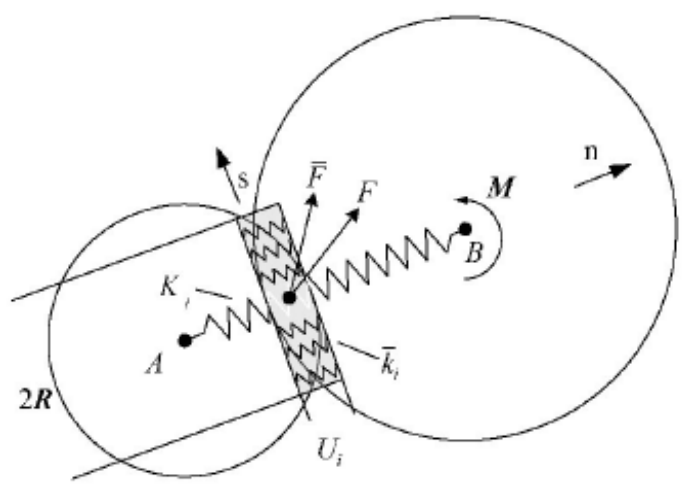

Fig.1. Parallel bond model of particle elements

Modeling of the test system. The model of test system of drop hammer test was shown in Fig.2. The establishment of concrete meso-scale mechanics model mainly includes two parts: the generation of meso-scale geometrical model(the generation and dropping of random aggregate) as well as the identification of meso-scale components including aggregate, mortar and interface[9].

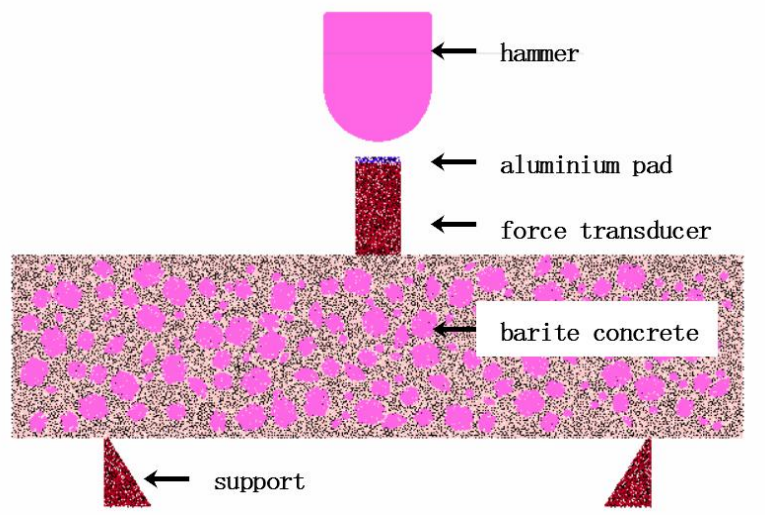

Fig.2. model of the test system

This model consists of three parts, the main part is barite concrete beams with dimensions of 100 $\mathrm{mm} \times 400 \mathrm{~mm}$, which includes barite aggregate, mortar and interface; The loading system includes the transducer and the hammer, the hammer in the shape of U was imported by CAD; Finally, the support system contains the aluminium pad and the support, both of which are composed of particles and assigned with corresponding parameters.

Calibrations of meso-scale parameters. A range of macroscopic mechanical parameters were got via related static tests of barite concrete beam[10], which is illustrated in Table 1.

Table 1. Macro-scale parameters of barite concrete beam

\begin{tabular}{ccccc}
\hline $\begin{array}{c}\text { Dimension } \\
(\mathrm{mm})\end{array}$ & $\begin{array}{c}\text { Compressive } \\
\text { strength } \sigma(\mathrm{MPa})\end{array}$ & $\begin{array}{c}\text { Elastic modulus } \\
\mathrm{E}(\mathrm{GPa})\end{array}$ & $\begin{array}{c}\text { Apparent density } \\
\left(\mathrm{kg} / \mathrm{m}^{3}\right)\end{array}$ & Proportion of mixture \\
\hline $400 \times 100 \times 100$ & 38.4 & 25 & 3350 & $1: 0.52: 3.27: 5.33$ \\
\hline
\end{tabular}


The meso-scale parameters of parallel bond model in PFC2D are density, kn, ks, pb_kn, pb_ks, pb_n, pb_s, etc. Among them, density means particle density, which was calculated by the concrete density and porosity; $\mathrm{kn}$ and ks represent normal stiffness and shear stiffness; pb_kn and pb_ks represent normal bond stiffness and shear bond stiffness; meanwhile, pb_n and pb_s mean compressive strength and shear strength. For the reason that these parameters can not be directly got from macroscopic material mechanical performance test, all the meso-parameters are determined by inverse analysis according to macro-experiment[11], the specific steps are as follows:

1. The radius of particle unit is controlled between $1.2 \mathrm{~mm}$ to $1.8 \mathrm{~mm}$ by changing the porosity(the porosity of this model is 0.24 ), which meets the Gauss distribution.

2. Assuming the elastic modulus and strength ratio of the three-phrase(i.e., aggregate, mortar and interface), then kn and pb_kn can be converted to elastic modulus by Eq. 1 and Eq. 2. Finally, inverse the ratio of $\mathrm{kn}$ and $\mathrm{ks}$ of the three-phrase.

$$
\begin{aligned}
E & =\frac{k n}{2 t} \\
E & =\frac{p b \_k n}{\left(R_{a}+R_{b}\right)}
\end{aligned}
$$

(2)

3. The values of $\mathrm{kn}, \mathrm{ks}, \mathrm{pb} \_\mathrm{kn}$ and $\mathrm{pb} \_\mathrm{ks}$ are ensured on the basis of elastic modulus of barite concrete beam.

4. The values of $p b \_n$ and $p b \_s$ are determined by inverse analysis according to bending strenght and compressive strength.

\begin{tabular}{|c|c|c|c|c|c|c|}
\hline \multirow{2}{*}{ Category } & \multirow[b]{2}{*}{$\begin{array}{c}\text { Particle } \\
\text { density } \\
\rho\left(\mathrm{kg} / \mathrm{m}^{3}\right)\end{array}$} & \multirow{2}{*}{ Friction } & \multicolumn{4}{|c|}{ Parallel bond parameter } \\
\hline & & & $\begin{array}{l}\text { Normal bond } \\
\text { stiffness } \\
\text { pb_kn }(\mathrm{GPa})\end{array}$ & $\begin{array}{c}\text { Shear bond } \\
\text { stiffness } \\
\text { pb_ks(GPa) }\end{array}$ & $\begin{array}{c}\text { Compressive } \\
\text { strength } \\
\text { pb_n(MPa) }\end{array}$ & $\begin{array}{c}\text { Shear } \\
\text { strength } \\
\text { pb_s(MPa) }\end{array}$ \\
\hline Mortar & 2900 & 0.5 & 25 & 12 & 20 & 30 \\
\hline Aggregate & 3900 & 0.5 & 30 & 16.7 & 32 & 48 \\
\hline Interface & 2900 & 0.5 & 20 & 10 & 10 & 15 \\
\hline Hammer & 4200 & & 6 & 2.5 & 200 & 200 \\
\hline $\begin{array}{l}\text { Aluminium } \\
\text { pad }\end{array}$ & 2000 & & 5 & 2 & 20 & 20 \\
\hline $\begin{array}{c}\text { Force } \\
\text { transducer }\end{array}$ & 2000 & & 5 & 2 & 200 & 200 \\
\hline Support & 9000 & & 80 & 80 & 200 & 200 \\
\hline
\end{tabular}

The meso-scale parameters determined by inverse analysis are shown in Table 2.

Table 2. Meso-scale parameters for the test system

\section{Comparison and analysis of test and numerical results}

Varieties of time-history curves. To achieve the purpose of changing the strain stress, the speed of hammer contacting force transducer is controlled by changing the drop height in the field test. Thus, the hammer is assigned with different initial velocity in numerical simulation. Besides, related curves, got from the simulation, were discussed with test curves[10], which was illustrated in Figs.3,4 and 5. 


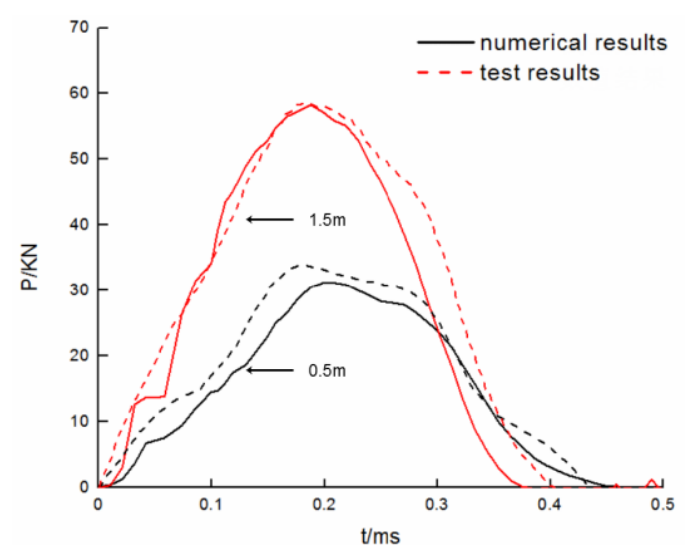

(a) when drop heights are $0.5 \mathrm{~m}$ and $1.5 \mathrm{~m}$

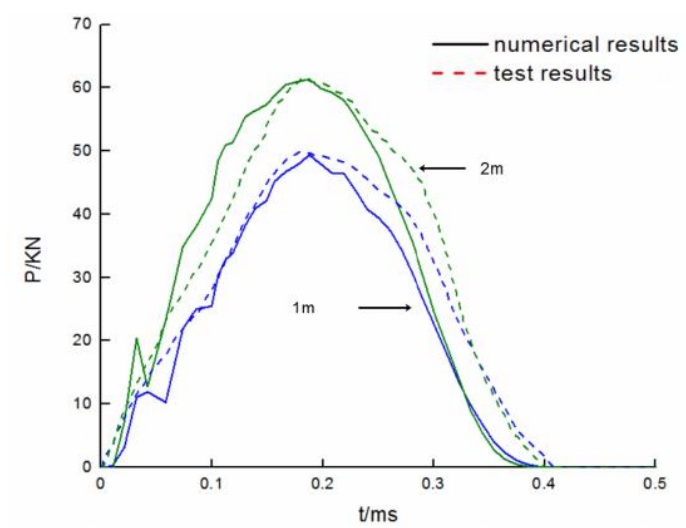

(b) when drop heights are $1 \mathrm{~m}$ and $2 \mathrm{~m}$

Fig.3. Comparison of test and numerical results of force histories

From Fig.3, we can know:

1. The numerical results show good agreement with the test results in terms of force histories. With the increase of drop heights, the peak load is on the rise and reaches a peak at approximately $0.2 \mathrm{~ms}$. Meanwhile, the loading rate increases continuously with the increase of drop height.

2. When the drop heights range from $1 \mathrm{~m}$ to $2 \mathrm{~m}$, the loading time around $0.4 \mathrm{~ms}$ tends to be stable. While the loading time differ from others under condition of $0.5 \mathrm{~m}$ for the possible reason that the impact velocity and strain rate tend to decrease under condition of low drop height, which was well verified by numerical results.

In fact, acceleration histories was obtained by monitoring the acceleration in the simulation, so it is necessary to obtain the vertical deflection histories through quadratic integral to acceleration histories, as shown in Fig. 4.

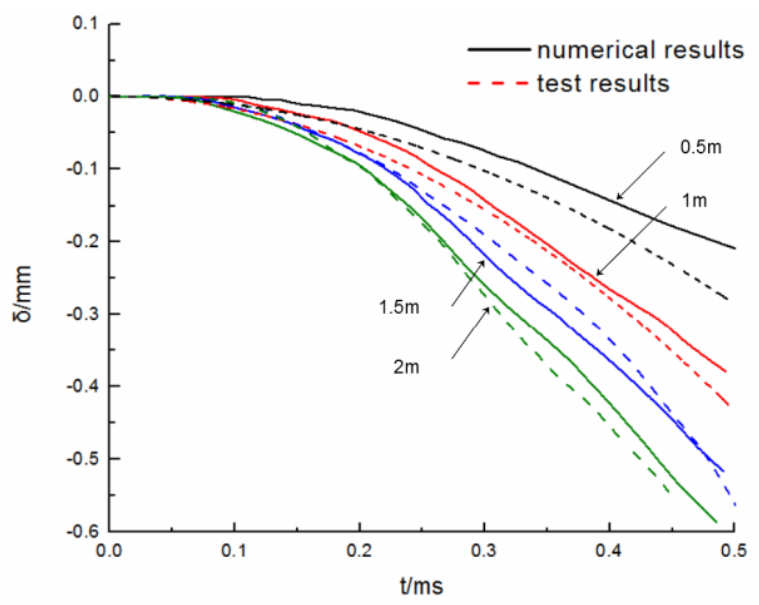

Fig.4. Comparison of test and numerical results of vertical deflection histories 


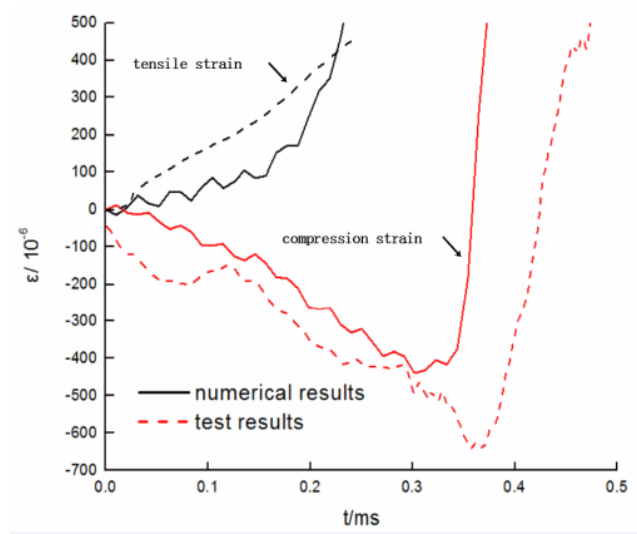

(a) $0.5 \mathrm{~m}$

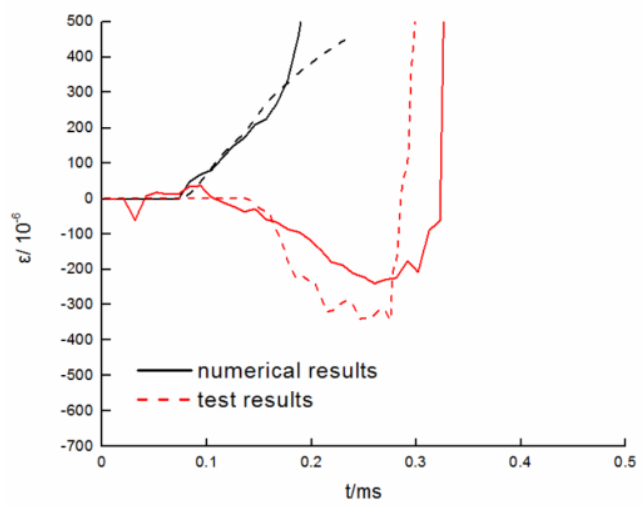

(c) $1.5 \mathrm{~m}$

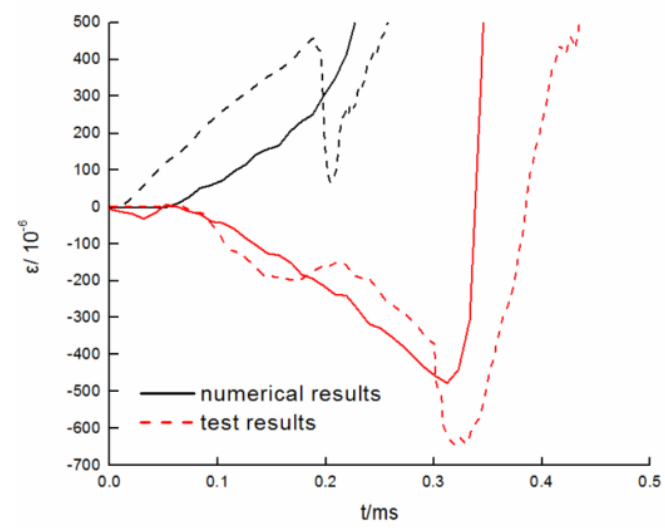

(b) $1 \mathrm{~m}$

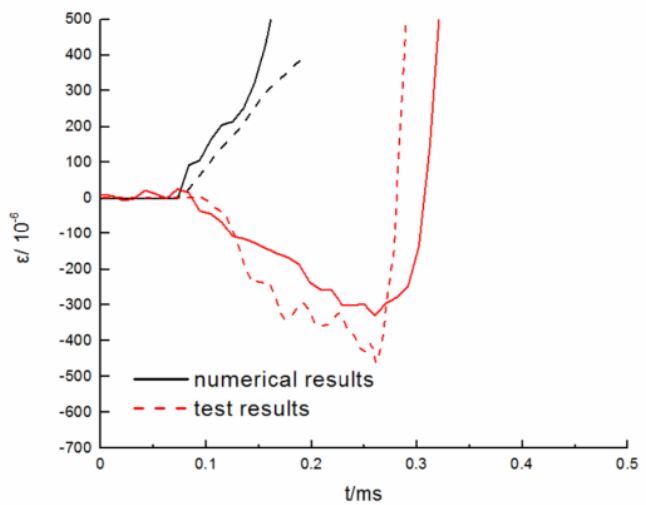

(d) $2 \mathrm{~m}$

Fig.5. Comparison of test and numerical results of strain histories

Dynamic increase factor. In order to characterize the dynamic strength of concrete, strain rate before initiation time was recorded and regarded the ratio of crack load and static carrying capacity as the DIF(Dynamic increase factor). Discussions were carried out among test results, numerical results and a large number of experimental results of the modified comite Euro-Inter-national du Bétonthe(M-CEB)equation by Marlver and Ross, which were illustrated in Fig. 6. It is found that dynamics strength coefficients of concrete got from test and simulation are greater than the one from equation, since there are different samples in the test to obtain the M-CEB equation. Still, from the prospective of statistical average, it matches well with the M-CEB equation, which verified the rate effect of barite concrete beam accurately.

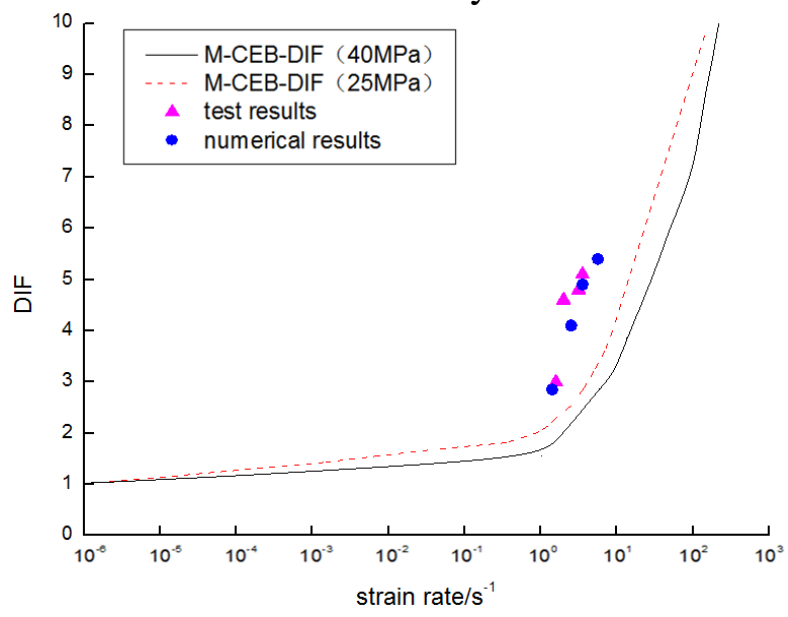

Fig.6. DIF versus strain rate

Cracking profiles. Failure phenomena of barite concrete beam in test and simulation was illustrated in Fig. 7, and it is suggested:

1. Spreading from the bottom, all the cracks of barite concrete beam run through the aggregate instead of the interface, which differs from crack development model of common concrete and proves the brittleness of barite. 
2. Note that in the case with drop height of $1 \mathrm{~m}$, a single crack is observed in current tests and simulation, which tends to be clearly parallel with the short side of concrete in the tension zone(Figs. $7 \mathrm{a}$ and $7 \mathrm{~b}$ ). It appears a bifurcation pattern and has more fragments in the tension zone in

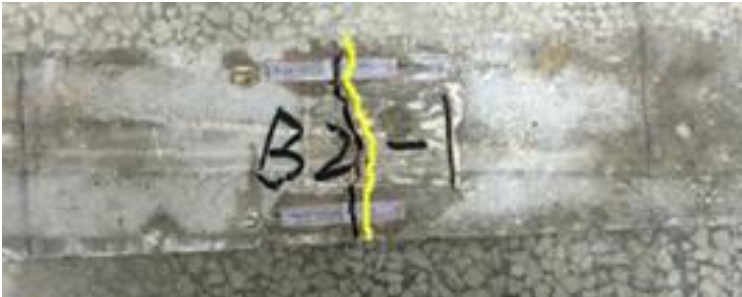

(a) test with drop height of $1 \mathrm{~m}$

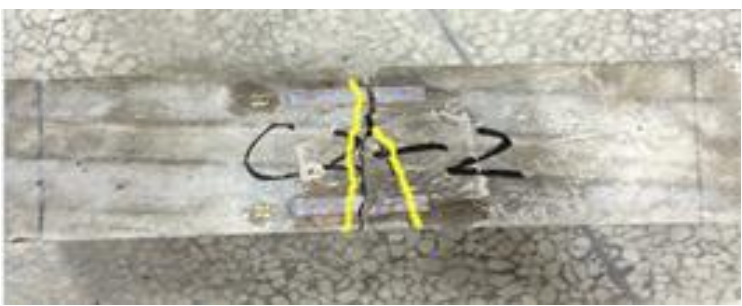

(c) test with drop height of $2 \mathrm{~m}$

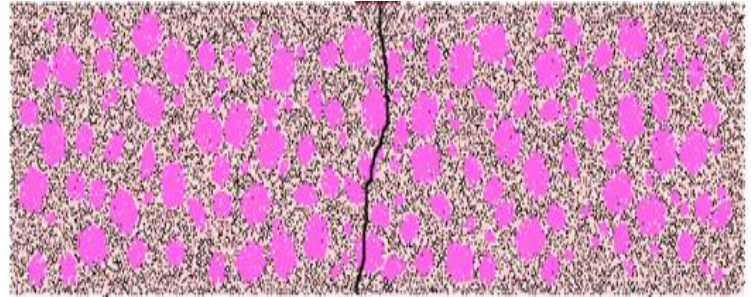

(b) simulation with drop height of $1 \mathrm{~m}$

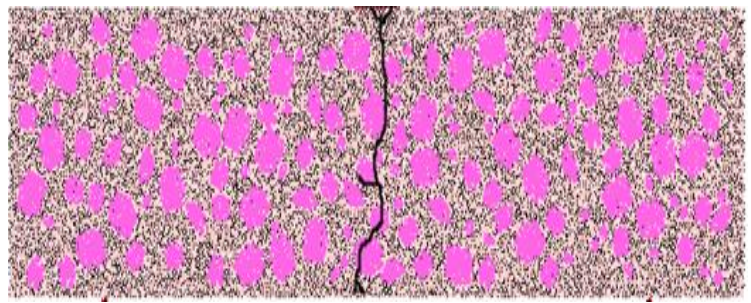

(d) simulation with drop height of $2 \mathrm{~m}$

Fig.7. Comparison of crack profiles in test and numerical simulation

the case with drop height of $1.5 \mathrm{~m}$ (Figs. 7c and 7d), and crack profile in simulation shows the similar phenomenon, which suggests strain rate has an impact on the development of cracks.

In order to further investigate the influence of strain stress on the development of crack, the meso-scale parameters were changing and the failure modes of barite concrete beam at high strain rate were illustrated in Fig. 8. Compared with Fig. 7, it was found that:

1. With the increase of strain rate, the input energy and the number of concrete cracks tend to be on the rise, and the crack bifurcation appear in some places.

2. The failure mode of concrete at high strain rates is completely different from the one at low strain rate, which suggests that the occurrence of more decentralized cracks is the key factor for the strain-rate effects.

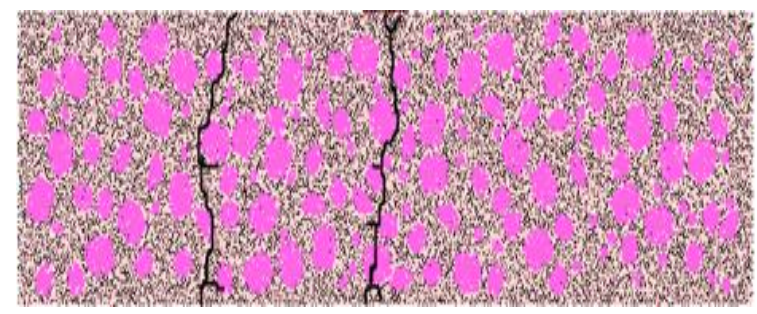

(a) Cracking profiles at strain rate of $6.6 \mathrm{~s}^{-1}$

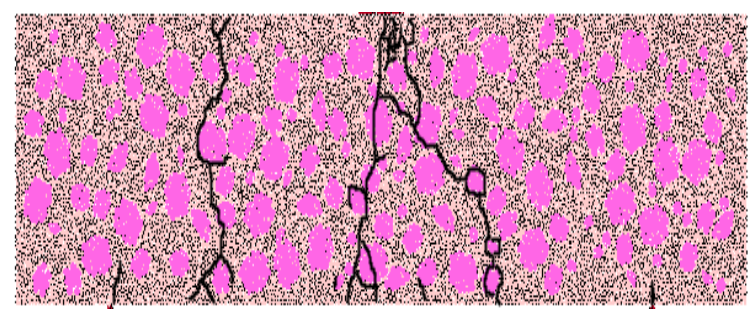

(b) Cracking profiles at strain rate of $8.8 \mathrm{~s}^{-1}$

Fig.8. Cracking profiles at different strain rate

\section{Conclusions}

Drop-weight tests for barite concrete beam are numerically simulated by using the meso-scale DEM mode in this paper, and general good results were achieved. By the comparison and analysis of test and numerical results, the following conclusions can be drawn from the study:

1. The constitutive relation and failure mode of barite concrete beam obtained from discrete element simulation match well with test results, which proved that the PFC2D software has good adaptability for simulating solid mechanics and particle flow problem.

2. With the increase of strain rate, the DIF of barite concrete beam in test and numerical simulation shows a tendency of increase, which matches well with M-CEB equation.

3. Based on test and numerical results, internal cracks of barite concrete beam run through the aggregate instead of the interface, which differs from crack development model of common concrete and proves the brittleness of barite. 
4. The failure mode of concrete at high strain rates is completely different from the one at low strain rate, which suggests that the occurrence of more decentralized cracks is the key factor for the strain-rate effects.

In this work, further study on major mechanism for strain-rate effects in concrete is not carried out in terms of energy dissipation, which still needs to be improved. It is found that PFC software has good adaptability for studying impact problem after simulating and showing its accuracy, which can generally reflect the impact behavior of concrete beam and would shed light on study of dynamic stability of structure.

\section{References}

[1] Yan Chen, Preparation and application of radiation shielding barite concrete, J. Building materials and decoration. 9 (2011) 425-426.(In Chinese)

[2] Yonghong Li, Jianbo Chen, Construction technology of Baryte concrete in the application of medeical building, J. Anhui architecture. 2 (2014) 41-41.(In Chinese)

[3] Chuhan Zhang, Discrete-contact-fracture analysis of rock and concrete, J. Chinese journal of rcok mechanics and engineering. 27.2 (2008) 217-235.(In Chinese)

[4] Wittmann F H, Structure of concrete with respect to crack formation, J. Fracture mechanics of concrete. 43.5 (1983): 6.

[5] Roelfstra P E, Sadouki H, Wittmann F H, Le béton numérique, J. Materials and Structures. 18.5 (1985) 327-335.

[6] Cundall P A, A computer model for simulating progressive large scale movements in blocky rock systems. Proc. Symp. Rock Fracture (ISRM), Nancy. Vol. 1. 2013.

[7] Cundall P A, Strack O D L, A discrete numerical model for granular assemblies, J. Geotechnique. 29.1 (1979) 47-65.

[8] Cundall P A, Strack O D L, Particle flow code in 2 dimensions, Itasca consulting group. Inc., 1999.

[9] Chuan Qin, Mingxin Wu, Chuhan Zhang, Impact splitting tensile experiments of concrete and numerical modeling by meso-scale discrete elements, J. Journal of hydroelectric engineering. 1 (2013) 196-205.(In Chinese)

[10] Chen Z F, Li T, The mechanical properties of barite concrete subjected to impact loading. In Advanced Materials Research, 2015, pp. 1369-1373.

[11] Qin Chuan, Zhang Chuhan, Numerical study of dynamic behavior of concrete by meso-scale particle element modeling, J. International Journal of Impact Engineering. 38.12 (2011) 1011-1021. 